\title{
Study of Business Process Reengineering implemented in Uttar Pradesh for the Transformation and Advancement of the Society
}

\author{
Dr. Saurabh Gupta ${ }^{1}$, Sameer Rajan ${ }^{2}$ \\ ${ }^{1}$ Scientist-'F' \& State Informatics Officer, ${ }^{2}$ Scientist- 'B' \& District Informatics Officer \\ National Informatics Centre, Ministry of Electronics and I.T., Govt. of India \\ NIC- Uttar Pradesh Unit, (India)
}

\begin{abstract}
Uttar Pradesh is the most populous state of India which is the home of more than 20 crores people or one-sixth of the country's total population. It is difficult to serve huge masses without the use of state of art technology and it is a herculean task for the government to maintain the huge databases of masses. The overall process of the Government was cumbersome due to the lack of technologies and ideas. But innovative uses of state of art technologies by the government are transforming the existing culture and resolving the associated issues. Now, government emphasizes to the sustained growth of the society through I.T. . To achieve this, Uttar Pradesh State Government focuses on various best practices and adopted process reengineering approach through various e-Governance initiatives in its modus operandi to make the system feasible for their citizens in which they may access the required services locally in affordable, efficient, transparent and time bound manner with minimum interaction to the government officials.

We study and explore the various issues in the existing system and adopted Business Process Re-engineering in existing system of the Uttar Pradesh Government for the transformation and advancement of the society in the direction of digital empowerment.
\end{abstract}

Keywords-- Process Reengineering, Transformation, e-Governance.

\section{INTRODUCTION}

E-Governance [1] is the process of enabling governance experts using Information and Communication Technology (ICT) to make governance effective for citizens in terms of efficiency, transparency, and cost-effectiveness. EGovernance [2] initiatives increase the chance that Government will facilitate social and economic benefits to citizens but the implementation of these initiatives requires structural, procedural, cultural and attitudinal change in the government. Developing countries are experimenting between automation and adjustments of government processes, and delivery of citizen adoptable initiatives. It [3] helps in achieving greater efficiency in government performance by raising service performance, and service delivery, by eliminating inefficient processes and reducing bottlenecks and red tape in the service delivery process as much as possible.

For the sustainable growth and affirmative transformation and advancement of the society, the process re-engineering of the government processes are required so that the e-
Governance initiatives may be successfully implemented and the society may take the advantage of them. Reengineering is best known in the private sector and is now infiltrating government. Many government organizations are scrambling to understand and initiate reengineering for their own service and product delivery business processes. Many international government agencies are adopting the process reengineering approach to start with a high-level assessment of the organization's mission, strategic goals, and citizen needs.

The process reengineering in healthcare [4] is to support the infrastructure of medicine in USA. Process Reengineering in the healthcare organizations is helpful to improve effectiveness of Health Information Systems. It redesigns the process, particularly in integration of multiple processes and process automation. Also [5] is based on the findings from two research projects in Mexican port subsector and shows evidence that business process reengineering is a viable tool for government reform in Latin America

India's e-governance transformation initiatives started in the 1990s. Since then the country has made considerable progress in the information and communication technology sector. To improve IT performance and productivity, the Government of India approved the National e-Governance Plan (NeGP) [6] on May 18, 2006 which seeks to improve delivery of government services to business and citizens establishments with the vision to "make all the government services accessible to the common man in his locality, through common service delivery outlets and ensure efficiency, transparency and reliability of such services at affordable costs to realise the basic needs of the common man". The NeGP initially comprised of 27 Mission Mode Projects and 10 Components. There are now over 7000 websites related to the Indian government offering informational and transactional services. DeitY is the principal institution for policy making in e-Governance and provides assistance in process reengineering.

[7] analyzes the performance of an e-Governance implementation for motor vehicle registration. Registration of new vehicles is a process which calls for detailed Government Process Re-engineering study as the frequency of this process is very high, to the tune of several lacs per year, and is increasing day by day. The objective of 
implementation of the e-Governance project is to register a new vehicle in less than five days. It also comes up with a reengineered process, after eliminating non-value adding approvals and steps to minimize the delay in the process, thereby improving the overall productivity.

To adopt the business process reengineering in government, [8] a task force of administrative and technical people may be deployed for planning, monitoring and evaluating result based development and management of the online system for improving the overall performance of the government mechanism. Virtual comparison of new process with existing system may be done, performed observation and monitoring of factors that may influence the proposed process.

Government of Uttar Pradesh also adopted business process reengineering in its processes and functions for the betterment and digitally empowerment of the society.

\section{PROBLEM STATEMENT}

Technology plays vital role for business process reengineering. The study is focused on the various government services issuance process of Uttar Pradesh government to see whether the implemented project met the objective of delivering these services with transparent, affordable, time bound manner at citizen's doorstep. It also seeks to ascertain whether these set objectives could be further improved through the implementation of the reengineering process. We also study to ascertain whether the government process engineering process in Uttar Pradesh really impact on the society for their transformation and advancement.

\section{RESEARCH METHODOLOGY}

The history of e-Governance in the form of Land Records in Uttar Pradesh begins with client server based Bhulekh software in 1998 to speed up the Record of Rights/Khatouni generation and reporting process. Revenue of Rs. 268 crores has been generated by distribution of 17.68 crores of Record of Rights (RORs) through Tehsil Centres, Lokvani Kendra and CSC Centresmaking computerization plan Self Sustainable. Then further evolution of process reengineering began for UP Bhulekh System. The state of art technology in the form of Cloud based Integrated BhulekhVer2.0 System which is an innovative model of Cloud Technology with Process engineering model of Land Records to disseminate and consolidate the relevant information regarding Land, the biggest cause of disputes resulting court cases. The Bhulekh System integration with CSCs also ensures the low level service delivery with transparency, and integration with Registry Department, Bank, Bhu-Naksha and UIDAI, digitally empowers the society. Availability of RORs on mobile is another evolution in khatouni system in the form of $\mathrm{m}$-Governance. Using this model the corrupt practices and harassment of citizens are minimized due to the automation of entire process flow and integration with other systems. Thus, the cloud based Bhulekh also makes an effective and efficient delivery of associated services like Registry, Subsidy, Loan, Financial Aid, FasalBeema, KisanBeema services etc. Now the villagers do not need to approach tehsil offices to get Right of Records (RORs)/ Khaounis. They just print it out from internet enabled café/CSCs.

The scholarship schemes play a vital role in socio economic growth and empowerment of weakersection of the society.SAKSHAM is the government process reengineered model of scholarships developed and implemented in Uttar Pradesh to interact, interface and transact with all the concerned stakeholdersin a integrated and interoperable manner for disbursement of scholarship and fee reimbursement in transparent, time bound, effective and efficient manner, directly into the bank account of downtrodden students. The objective of the reengineering is not to generate revenue however to save a lot of revenue indirectly by minimizing the leakage of funds. It also speed up the disbursement process, filters the fraudulent claims, finds the deduplication of claimants. Table I shows the scholarship statistics for the session 2016-17. It may be noted that only 6460272 applications forwarded and remaining are rejected which shows the filtration of valid applications.

Table I. Session 2016-17 Scholarship Statistics

\begin{tabular}{|l|l|l|l|l|l|}
\hline Session 2016-17 & Total Colleges & Registrations & Form Entered & Final Submission & $\begin{array}{l}\text { Forwarded } \\
\text { Institutions }\end{array}$ \\
\hline Post Matric (11-12) & 16510 & 2478001 & 1805368 & 1590074 & 1380770 \\
\hline Post Matric (Institute) & 11263 & 6444226 & 4776443 & 4350625 & 3823460 \\
\hline Pre Matric (9-10) & 30403 & 2719857 & 1661937 & 1460911 & 1256042 \\
\hline Total & 58176 & 11642084 & 8243748 & 7401610 & 6460272 \\
\hline
\end{tabular}

Process reengineering has been adopted in the departments of Govt of Uttar Pradesh which issue citizen centric services like Caste, Domicile, Income, and Marriage Registration services in the form of online citizen services portal. It is to transform the existing process pervasive in our society by enabling a single point of access to the citizen services and associated information being provided by the various state Government departments at citizens ${ }^{\text {ee }}$ doorstep with total transparency, and with grass root level participation.Government aims to change the service delivery process life cycle to ease the existing system for their citizens. Initially, all the processes required to provide any service to the citizens were based on manual exercise. It used to create huge loads and difficulties to provide services with transparency, affordable and time bound manner with limited man power.These citizen centric services like Caste, Domicile, Death and Birth Certificates etc are very important for all the stakeholders. The citizens are empowered to claim for related benefits/ schemes on the basis of these services/ certificates. Also, the Government may filter the valid claims by verifying these documentary proofs. Various reports/ surveys may be done 
which give idea to form new policies and schemes for the transformation of the society. Initially, the system followed the manual work culture so the citizen manually applies for citizen centric certificate to tehsil office they process huge applications and provide the certificate to the concerned citizen. It requires unnecessarily time delay, mediators role, bribe demands, opacity etc. To avoid such things, process reengineering was done to resolve the existing system and eDistrict and Online Citizen Services Portal were developed and implemented for the citizens. It is fully automate the process and the citizens get the required services without approaching any offices and within time frame. The number of highest eTransactions of the services are Caste certificate and Domicile certificates which are $8,73,366$ and 6,53,983 respectively and more than 34 lacs of e-Transactions of all the certificates have been done.

Initially, the complaint redressal system was not transparent and efficient. The proper action was not used to take on citizen's complaints. The lack of proper monitoring was also the reason. The process reengineering has been adopted for the flow of complaints received and redressal mechanism of various departments and divisions of the government. The process reengineering of complaint received by government offices was done and a flow based system has been developed and implemented. Integrated Grievance Redressal System (IGRS- Jansunwai) is an integrated system for grievance redressal in Uttar Pradesh to achieve the goal of good governance using latest technology involving all stakeholders. A citizen can freely and conveniently file a grievance, track the grievance lodged on all important platforms and receive response to his satisfaction both in terms of quality and time. Along with lodging of complaints, citizen can also interact with Government/Departments/Offices in an easy and transparent manner. Complaints from all sources will be available on a single platform to all departments which will improve access, redressal and monitoring. Now complainant may file any complaint at any level (PG Portal, CM Office, DM Office etc), and his complaint would be resolved in time bound manner and also the monthly progress report is prepared by IGRS System of all the officers. The monitoring of this system is automatic with the use of state of art technology. So the officers are bound for qualitative and timely disposal of complaints. Now, nobody can complaint that the police is not taking action or any officer is not receiving complaint and taking no action on his complaint

Earlier, the service delivery of government was not up to the mark. The needy had to come government offices for required services but after the process reengineering in the delivery chain, now the services have reached at citizen's doorstep. To give the thrust to government services delivery life cycle, Common Service Centers play a vital role in effective and efficient service delivery at citizen's doorstep. CSCs facilitate various $\mathrm{G} 2 \mathrm{C}$ and also G2B services. The price of $\mathrm{G} 2 \mathrm{C}$ services (Caste, Income, Domicile, RORs/ Khaounis etc) are fixed by government. Each Gram Panchayat has been targeted to open atleast one CSC for the delivery of government services at villager's doorstep in economical and transparent manner. It was not easy task due to the lack of official staff, training, infrastructure and fund. But by taking the matter seriously and strategically, we make this herculean task possible and Uttar Pradesh has the largest CSC Network comprising of 44,999 CSCs in Gram Panchayats in the year 2015-16. Shamli is the first district which opens atleast 01 operational UP-CSCs in all the gram panchayats of the district.

The vehicle registration and the Learner License/ Driving License were issued manually but the process reengineering of the transport department resolve the issue of unnecessary delay and mediator's role. Now the citizens may book the license test slot online. The calculation of fees for various services like addition of hypothecation, alteration of vehicle, conversion of vehicle, transfer of ownership, new registration, renewal are automatic. It curtails the loads of transport office which speed up the generation, distribution of license and vehicle registration process. More than 75 thousands of e-Transactions for these services have been executed successfully.

It is noted that more than 12 crores transactions have been done since implementation of the business process reengineering in the mechanism of Uttar Pradesh government. Table II. shows the number of e-Transactions for few standard services issued by Uttar Pradesh.

Table II. E-Transactions Statistics

\begin{tabular}{|l|l|l|}
\hline S. No. & Standard Services & No. of e-Transactions \\
\hline 1 & Utility Services \& Bill Payment & $5,12,74,644$ \\
\hline 2 & Commercial Tax & $2,68,19,834$ \\
\hline 3 & Social Welfare \& Pension & $1,13,79,745$ \\
\hline 4 & Employment & $38,32,038$ \\
\hline 5 & Health & $35,53,413$ \\
\hline 6 & Certificates & $34,46,652$ \\
\hline 7 & Integrated Finance Management System & $9,58,486$ \\
\hline 8 & Transport & 75,852 \\
\hline 9 & e- Procurement & 55,564 \\
\hline 10 & Industry \& Commerce & 2,702 \\
\hline
\end{tabular}

\section{CONCLUSION}

The system redesigned after government process reengineering is not always adoptable by the stakeholders because it involves structural, procedural and attitudinal change. The stakeholders have a tendency to fall back on earlier method by finding the drawbacks. Gradually, due to the effectiveness and efficiency of the system all adopt the change. It requires the proper analysis of the system. More than 12 crores of e-Transactions have been executed. It 
shows the adoptability of process reengineering in the government processes by various stakeholders.

Uttar Pradesh is continuously adopting the process reengineering approach to develop and implement the eGovernance ideas by evolving and adopting the state of art technology so that government process may be more economical, feasible, affordable, transparent and time bound.We have taken few sectors/ departments/ eGovernance initiatives of the government for the study in which the process reengineering have been adopted to transform the existing work culture so that citizens may get the advantage of it. These initiatives ensure the citizens that they are not required to unnecessarily approach to any office, they may get these services through online portals and CSCs. The Government Process Reengineering is playing a vital role for the transformation and advancement of the society to make the Digitally Empowered StateUttar Pradesh.

\section{REFERENCES}

[1] R.K. Sapru and YudhishthiraSapru, "Good Governance through E-Governance with Special Reference to India", Indian Journal ofPublic Administration Vol. LX, No. 2, AprJun 2014.

[2] Jim Yonazi et al., "Exploring Issues Underlying Citizen Adoption of eGovernment Initiatives in Developing Countries: The Case of Tanzania", Electronic Journal of eGovernment Vol 8 Issue 2010.

[3] Quinta Nven-akengNkohkwo et al., "Challenges to the Successful Implementation of e-Government Initiatives in Sub-Saharan Africa: A Literature Review", Electronic Journal of e-Government Vol. 11 Issue 22013.

[4] SoudabehKhodambashi, "Business Process Re-Engineering Application in Healthcare in a relation to Health Information Systems", Science Direct, Procedia Technology 9 (2013) Pages 949-957.

[5] Jaime Torres Fragoso, "Business Process Reengineering in Government Agencies: Lessons from an Experience in Mexico", Journal of Service Science and Management, 2015, Page 382-292.

[6] NeGP, "National e-Governance Plan", available at http://meity.gov.in/divisions/national-e-governance-plan (accessed on 12 May 2017).

[7] Suresh Subramoniam and Dev Twinky, "Government Process Re-engineering of an E-governance Implementation for Motor Vehicle Registration in India", Indian Management Journal, Vol. 6 Issue 2, July- Dec 2014.

[8] Dr. Saurabh Gupta and Sameer Rajan, "SAKSHAM: A Government Process Reengineered Model for Scholarship and Feereimbursement and its Impact on Society- A study of Uttar Pradesh, the most populous state of India", IJRDOJournal of Educational Research, Volume 2 Issue 2, Feb2017. 